\title{
Research on the Modularized Instructional Design of Graphic Design in Higher Vocational Colleges
}

\author{
Zhu Ding \\ Chongqing College of Electronic Engineering, Chongqing, China,401331 \\ email:632126716@qq.com
}

Keywords: Modularized Instructional Design, Graphic Design, Higher Vocational Colleges.

\begin{abstract}
At present, the rapid development of science and technology, computer software has been widely introduced to the major colleges and universities in the art design profession effectively help to optimize its teaching process. However, due to the current development of information technology in the process, the computer software, hardware applications there are many deficiencies in the software teaching, more emphasis on software functions and command teaching. And in recent years, there are still many shortcomings and problems in the design process of software, which further requires that higher vocational education should be realized and proceed from reality. According to the current development of higher vocational education in China, the teaching of software from the ideology and mode to reform and improve and further optimize the design of teaching structure.
\end{abstract}

\section{Introduction}

The introduction of computer software into college art design professional teaching is started in the 20th century, China began in the 20th century, the beginning of the 21st century, Chinese computer hardware and software development is not yet mature, the software teaching mainly around some basic functions and orders to start. Since 2005, there have been some new problems in the design software learning, which requires us to pay attention to the teaching of higher vocational education and pay attention to these changes, combined with the characteristics of higher vocational education, software teaching ideas, teaching methods to adjust the teaching of structure to re-design. The author explores the modular teaching as the main way in the actual teaching of the plane software, and tries to carry on the overall design of the software teaching through the course.

In the teaching process of graphic design professional software in higher vocational education, the present teaching situation is still in the general sense of function introduction and basic command operation level. In order to speed up the quality level of professional software teaching and to meet the needs of social talents, the paper divides the course into basic modules of basic skills and application skills to explore the new ways of graphic design software teaching in higher vocational colleges.

\section{The Teaching Mode on the Graphic Design Software Modular}

In the modular software arrangement of the plane software, you should first divide the graphic design software course into two parts. The two parts can be divided into basic ability and application practice ability. Then, for the two different contents, the actual departure, in turn these two parts are divided into many small branches. In terms of basic competencies, we pay more attention to some systems, basic and relatively comprehensive problems in technical education. The application practice ability lies in solving the problem of whether the skills in the development of technical education can be innovated and further deepened.

The Teaching Design on Basic Skills Module. The establishment of the basic skills module, its premise and the foundation is to learn the object of the overall understanding and understanding, 
and have a certain skill basis, the establishment of the corresponding teaching content, and teaching objectives of the software on the most basic content learn. However, this basic skills cannot be separated from a specific design process, and thus in the process, the presentation method and the solution to the basic skills into the module, and create a practical module with the actual content of the specific by comparing the comparative teaching method of horizontal teaching methods to further compare the similarities and differences between the relevant software, and thus the functional areas of the software have a more comprehensive and clear understanding to take a solution to the problem to further explore the specific operation of the software function and its operational skills to consolidate the study and flexible use, to achieve the same problem in the context of the software can be a reasonable and effective application. The practical application of the teaching method to solve the problem must be some very basic order of the software, tools should be more familiar with and understand, and solve the problem of solving the problem, and then find out how to solve the problem and get it to answer must pay attention to the use of the problem to solve the implementation of the solution, the problem is best proposed is relatively simple, and the teacher in the software application skills to give students some correct guidance, to achieve the effect of teaching guidance and quality.

Specific Teaching Design of Application Skill Module. In the process of teaching the application of skills modules, should be cross-border teaching ideas and models into one. In the specific teaching process of the application skill module, the core content of its teaching is the skill application. First, the fundamental nature of teaching should tend to professional goals, and in order to further deepen the teaching process, can be out of the software itself, the knowledge and skills of teaching guidance. Through this cross-border to achieve the application of other software has a field of extension of the extension of teaching, and thus extended to other software-related technology, technology and other areas, combined with teaching. The project can be derived from the actual situation in the class taught by the teacher, as the teacher can choose from the existing teaching resource library to select the project, you can also carry out independent development projects to achieve the ultimate completion of the physical teaching purposes, the selection of such projects The process of completion will make the teaching place more mobile. Students in the learning process, not only need to design the effect of business cards, but also in the design of business cards in the specific practical activities, combined with the relevant design software to connect the knowledge and process in-depth study, the workplace will be from the classroom to a variety of plate companies, paper companies and printing agencies.

\section{The Graphic Design Software Modular Teaching Methods}

Module 1: Basic Skills Module Teaching Design. The basic skill module is a teaching setting based on the establishment of some kind of holistic understanding and mastering the basic skills. At this stage, the teaching goal is to make a holistic and basic learning of the software. But the acquisition of basic skills also needs a special design process, for which we introduce the basic skills in the comparative demonstration method and ask the solution, the design of specific modules teaching content. Through the horizontal comparison of the demonstration method to deepen the similarities and differences between the relevant software to establish a clear field of software work and a holistic understanding; through the solution to explore the software operating skills, and further understanding and flexible application of these skills and in different flexible use of the problem context.

In the horizontal comparison demonstration, we use the software "regular" control panel as an example of comparative demonstration teaching. This follow-up of specific learning will have a general and fundamental impact on the application of technical application module is very important.

The solution is based on the understanding of the basic tools and the simple operation of the basic order, and the problems of the solution are put forward. First, the solution is solved and the specific problems are solved. In the use of questioning solution should pay attention to the contents of the question should not be too complicated, teaching teachers to grasp the guidance of skills, and 
timely teaching results to sum up. As we have used this question in teaching: "After drawing the basic operation of Illustrator's radio and round tool, we have done a drawing of Tai Chi graphics." This standard drawing of graphics is completely different from traditional painting under normal circumstances, students will be in a period of time after the exploration of the direction of the solution, which requires teachers to ask and lead students to solve the problem, and finally to solve the process to sum up.

Module 2: Application Skills Module Teaching Design. Application of skills module teaching we have introduced cross-border educational ideas and methods. Where the cross-border is to cross the boundaries of the software itself, extended to the field of software applications associated with each other, and these areas of technology, technology and software skills, organic combination of skills.

Application module teaching content of the first part, PS and AI are using the project teaching method. The source of the project needs to be combined with the actual situation of the teaching class, which can be developed by the teacher or selected from the existing teaching resource library. However, the final result of the teaching must be completed. This will promote the flow of teaching places. Such as designing a company's business card, seemingly simple design depth implementation will involve multiple cross-boundary solutions in the field. Students to learn not only the effect of the design of the business card, but through the design of business card activities, connecting the relevant knowledge, technology and technology at the same time learning, workplace also followed out of the classroom, into a variety of paper companies, plate companies and small print organizations. Technically they have to complete the business card design in the classroom selection, design with color, bleeding settings, fonts, font size and printing requirements, and whether the use of decorative ink effects, spot color prepress design and other details of the problem.

In the second part of the application module teaching content, from the PS in the color and channel, channel and plate comparison, understand the color, channel, spot color, output, plate, printing and other processes. Cross-border makes the teaching process from software to non-software association domain, and these career applications related to the comparison, can clearly explain the role of the channel in the color settings and the relationship between printing and related technical requirements.

In the cross-border comparison of teaching, professors and learners often encounter a variety of different problems, teaching units can be based on their own specific circumstances to strengthen the Institute of cross-border teaching aids research and development work. The physical form of teaching and researching work can, in a way, play a balance or alleviate the problems that exist in the cross-border teaching with the existing teaching system, the separation of the university from the business environment, and the resulting teaching and actual separation problem.

In the areas where the project practice conditions are relatively mature, the project design and the cross-border comparison method can be combined to implement the teaching activities. In the areas where the conditions are not mature enough, we should try to expand the mature and effective external teaching conditions. Work to ensure that the basic nature of cross-border learning remains the same while studying at school. This specific course points to the development of teaching aids with obvious technical decomposition and cross-border nature. We compare the teaching of cross-border teaching aids, the color of the color in the software and the contrast of the physical color, to explain the spot color settings in the software will not flow in the abstract and imagination, but directly to the needs of the profession.

\section{The Improvement of Cross - Border Teaching Methods of the Comprehensive Teaching Ability of Teachers}

In the graphic design software of higher vocational education, the teacher must be rich and solid in the professional experience, especially in the practical experience of the occupation, so as to give the students the correct and efficient teaching instruction in the cross-boundary solution teaching process. Under normal circumstances, if it is a business staff and is in the enterprise of graphic 
design software application practice ability is very strong, can be used as a high school graphic design software instructor; also has a strong academic experience of the teacher through the enterprise training and then teaching work, but the most desirable one is experienced in the enterprise staff to teach high school guidance. Second, as a "double teacher" teacher, on the one hand in the professional experience to have a more solid foundation, but also to master the teaching methods to further enhance students in cross-border learning in the study of learning ability, and effectively design a " ask the solution of the practice of the project ", making the graphic design software modular teaching more vivid and flexible. Teachers should be able to design and master the relevant requirements of module teaching, in the basic technical module teaching stage, the effective design of the "ask the solution of the practice project" to promote basic skills teaching vivid, flexible and deepening. In the application of technical modules teaching stage, combined with the specific requirements of professionalism, leading teaching gradually deepening. Finally, teachers should actively participate in the development of teaching conditions and teaching aids research and development work. Teachers as the main body of education construction, should actively participate in the design and implementation of the teaching, the external environment, strengthen the teaching facilities and teaching aids research and development work to adapt to the continuous development of the educational environment.

\section{Conclusion}

To sum up, in the teaching process of modular software for high-level graphic design software, the goal of concrete teaching of graphic design software should be established, and the structure and level of teaching process should be clarified, and teachers should be promoted professionally the level of comprehensive teaching skills, in order to promote the sustainable and stable development of vocational software teaching, so as to enhance the quality of teaching and learning throughout the higher vocational education.

\section{References}

[1] Zhang Lei, Shang Xiaolei, Cheng Zhuo, Liu Chao. Exploration and Practice of "Plane Design Software" Teaching Diversification in Higher Vocational Colleges[J]. Journal of Shijiazhuang Vocational and Technical College 2011 (02)

[2] Zhongzhi. Graphic design software collaboration skills[J] .Computer and Network. 2002 (24)

[3] Zhao Bin. On the Practical Application of Computer Graphic Design Software[J]. Journal of Computer Applications, 2014 (18)

[4] Tang Chan. On graphic design software in the graphics rendering technology[J]. Computer Knowledge and Technology. 2011 (08)

[5] Wang Shixiao. Graphic design software in ceramic flower paper design application [J]. Art Education Research. 2011 (04)

[6] Ding Xiaoyan. "Graphic Design Software" training course project design analysis[J]. Vocational Education Research. 2011 (11) 